\title{
OPTIMIZATION OF PACKING OF LOCAL COARSE AGGREGATES FOR USE IN UHPC (ULTRA-HIGH-PERFORMANCE CONCRETE)
}

\author{
Juris Zavickis $^{1}$, Arturs Lukasenoks ${ }^{2}$, Arturs Macanovskis ${ }^{3}$, Maris Tupesis ${ }^{3}$ \\ ${ }^{1}$ Dzelzsbetons MB, Latvia; ${ }^{2}$ Betona pētījumu centrs, Latvia; ${ }^{3}$ Riga Technical University, Latvia \\ juris.zavickis@mbbetons.lv, arturs.lukasenoks@rtu.lv, arturs.macanovskis@rtu.lv
}

\begin{abstract}
Innovations in the construction industry require new and efficient materials, like ultra-high performance concrete (UHPC), that allows to develop and engineer unprecedented construction solutions. Aggregate packing gives a significant contribution to the final properties of concrete design and especially ultra-high performance concrete. High-quality coarse aggregates $(0-1.25 \mathrm{~mm})$ of local origin were used to investigate the packing density, consistency and compressive strength of ultra-high performance concrete for application in advanced prefabricated concrete products (facades, balconies, stairs, structural elements). Several sources of high-quality quartz sand pits in the Baltic state region were evaluated and fractioned quartz sand from Lithuanian company AB Anykščių Kvarcas was chosen for experiments. Optimization of the packing density was performed using different experimental methods: Punkte test and ICT testing. Wet and dry experimental methods of assessing void volume in the coarse aggregate mix were used. Different mixes of coarse aggregates were prepared and optimal paste/aggregate proportion was found to deliver necessary fresh concrete flowing properties and hardened concrete compressive strength of the final mix. Conclusions were made on possibility and feasibility to use coarse aggregates of local origin for the development of cost-efficient ultra-high performance concrete mix design for use in advanced prefabricated concrete products.
\end{abstract}

Keywords: high-performance concrete granulometry.

\section{Introduction}

Industry requests for continuously increasing cost effectivity of the concrete products at the same time developing higher mechanical performance. This can be done in bothways - increasing the mechanical properties of concrete and reducing costs for source materials. Recent development in ultra-high performance concrete (UHPC) technology provides increased mechanical properties over conventional concrete, thus less material can be used for products [1]. The packing density of fillers is noted as one of the key elements in the successful design of UHPC, as packing provides a clear indication of voids content, which must be filled with water-cement paste, nanofillers and air. According to literature, one of the most effective methods to obtain UHPC is to optimize the packing density of the fillers based on the characteristics of the raw materials measured beforehand [1]. In such a way the necessary amount of the nanofillers and water-cement paste may be greatly reduced resulting in price reduction of final product. However, the packing density of various fillers may be influenced by the shape of the particles from the particulate origin, that is why exact composition must be assessed for every combined mix of local filler ingredients. The composition of fractions, which possess the least amount of free voids, can be designed either theoretically (by combining grading curves of individual fractioned ingredients), either empirically (by compacting the fillers and assessing the volume of free voids by different experimental methods) [2]. As most of the concrete by mass parts consists mainly from inert fillers, the packing of filler should be optimized first, following by pozzolanic components and then - nanofillers. In this research the main focus is setto assess the easy to perform and affordable way to optimise the grading properties of quartz fillers of local origin. This may be one of the key factors to elaborate cost-effective UHPC in future suitable for industrial production.

\section{Materials and methods}

Availability of UHPC inert fillers was evaluated, taking into account the local resources of fractioned quartz sandpits, according to information provided by the Latvian Environmental, Geological and Meteorological Agency [3]. According to market research, there is limited availability of fractioned quartz sand of local or close local origin. It is offered only by 2 Baltic companies: Sia "Saulkalne S" (Latvia) and AB Anykščiu Kvarcas (Lithuania). The price of quartz filler greatly influences the commercial end price of the UHPC, thus AB Anykščiu Kvarcas was chosen between two available suppliers. The fractions used were as follows:

- fraction A - particle size 0.8-1.25 mm 
- fraction B - particle size $0.4-0.8 \mathrm{~mm}$

- fraction $\mathrm{C}$ - particle size $0.05-0.4 \mathrm{~mm}$

- fraction D - particle size less than $50 \mu \mathrm{m}$.

All fractions consisted of at least $98.5 \%$ pure quartz, with less than $0.05 \%$ of $\mathrm{Fe}_{2} \mathrm{O}_{3}$ and less than $0.6 \% \mathrm{Al}_{2} \mathrm{O}_{3}$ additions. The grading composition of each fraction according to the supplier is shown in Table 1-2.

Table 1

Grading composition of Quartz sand fractions A, B \& C showing weight \% passing sieve

\begin{tabular}{|c|c|c|c|c|c|c|c|c|c|c|c|c|}
\hline $\begin{array}{c}\text { Sievesize, } \\
\boldsymbol{\mu m}\end{array}$ & $\mathbf{6 3}$ & $\mathbf{1 0 0}$ & $\mathbf{1 6 0}$ & $\mathbf{2 0 0}$ & $\mathbf{3 1 5}$ & $\mathbf{4 0 0}$ & $\mathbf{6 3 0}$ & $\mathbf{8 0 0}$ & $\mathbf{1 0 0 0}$ & $\mathbf{1 2 5 0}$ & $\mathbf{1 6 0 0}$ & $\mathbf{2 5 0 0}$ \\
\hline Fraction A & - & - & - & - & - & 2 & 2 & 8 & 21 & 53 & 88 & 99 \\
\hline Fraction B & - & 1 & 2 & 3 & 6 & 20 & 91 & 100 & - & - & - & - \\
\hline Fraction C & 1 & 8 & 22 & 39 & 83 & 97 & 100 & - & - & - & - & - \\
\hline
\end{tabular}

Table 2

Grading composition of Quartz powder fraction D showing weight \% with less grain size

\begin{tabular}{|c|c|c|c|c|c|c|c|c|c|c|c|c|c|c|c|}
\hline $\begin{array}{c}\text { Grainsize, } \\
\boldsymbol{\mu m}\end{array}$ & $\mathbf{0 . 2}$ & $\mathbf{0 . 5}$ & $\mathbf{1}$ & $\mathbf{2}$ & $\mathbf{3}$ & $\mathbf{4}$ & $\mathbf{5}$ & $\mathbf{6}$ & $\mathbf{8}$ & $\mathbf{1 0}$ & $\mathbf{1 5}$ & $\mathbf{2 0}$ & $\mathbf{3 0}$ & $\mathbf{5 0}$ & $\mathbf{6 3}$ \\
\hline Fraction D & 1 & 3 & 6 & 13 & 19 & 24 & 28 & 32 & 38 & 43 & 55 & 65 & 83 & 98 & 100 \\
\hline
\end{tabular}

To determine the optimum grading composition of available inert quartz fillers, which possess best achievable packing (less free voids), two experimental methods were used: Punkte test [4] and Intensive compaction test [5; 6].

During Punkte test, a small portion (200g in total) of at least two materials with different grading properties are put into a cylindrical glass baker (0.2-0.31 volume) and dry mixed until a homogenous mix is obtained. Then clean tap water is added gradually and the mix carefully stirred. During the addition of water, the jar is continuously tapped onto the steady flat surface after each stirring, just until the surface of the mix appears glossy right after tapping, indicating that complete water saturation of the mix is obtained.

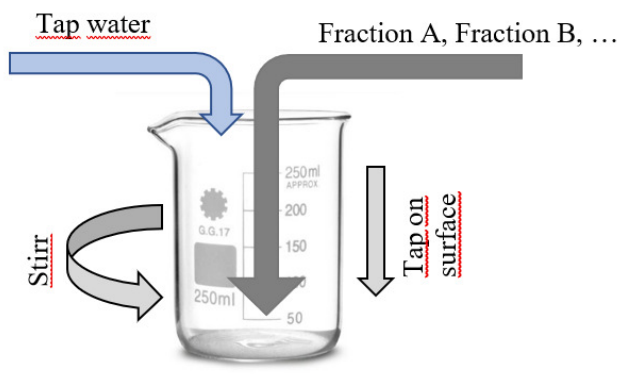

Fig. 1. Principal scheme of Punkte test

When such the saturation point is achieved, it has been noted as the lowest water demand necessary to saturate the current mix of components, which is then expressed as follows:

$$
M_{\text {waterdemand }}=\frac{M_{\text {addedwater }}}{M_{\text {drymix }}} \times 100,
$$

where $M_{\text {water demand }}$ - relative mass of added water at point of saturation, \%;

$M_{\text {added water }}$-mass of added water, $\mathrm{g}$;

$M_{d r y ~ m i x}$-mass of dry sample mix, $\mathrm{g}$.

Intensive compaction test is done using a special automated testing device. Thesample of fresh concrete (1.9-2.1 kg in total) is poured into a standardized steel cylinder mould and compressed under mechanically induced cyclic shear deformation. The IC test method was adopted by using it on a dry 
sample without water-cement paste, thus a portion of at least 2 materials was dry mixed together and put into the tester.

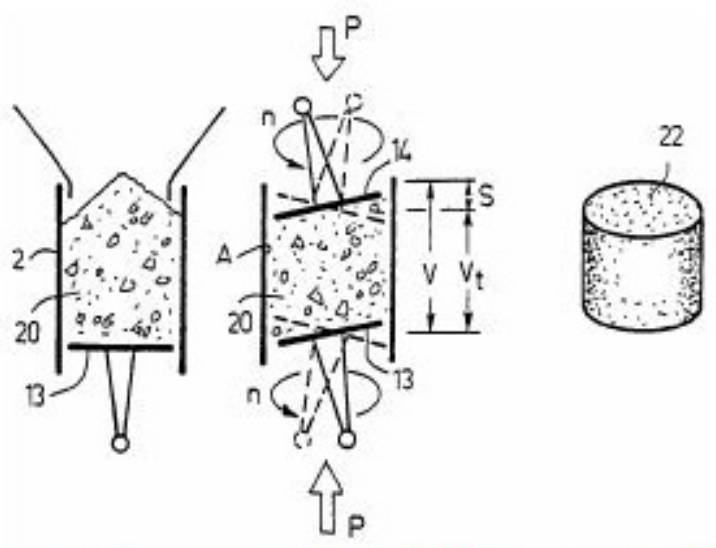

\section{Fig. 2. Principal scheme of Intensive compaction testing according to US patent 4,794,799 of Intensive Compaction Device}

During certain number of shear cycles the material improves its packing and after the compaction has ended, the final weight and volume of the sample are measured, the experimental density calculated and the relative volume of internal voids is calculated as follows:

$$
V_{\text {voids }}=\left(1-\frac{\rho_{\text {experimental }}}{\rho_{\text {calculated }}}\right) \times 100,
$$

where $V_{\text {voids }}-$ relative volume of voids, \%;

$\rho_{\text {experimental }}$ - experimental density of the compacted sample, $\mathrm{kg} \cdot \mathrm{l}^{-1}$;

$\rho_{\text {calculated }}$ - cumulative density, calculated from actual densities of single fractions, $\mathrm{kg} \cdot \mathrm{l}^{-1}$.

The actual densities of each fraction were measured using laboratory pycnometer according to LVS EN 1097-6 standard. The experimental density of the mix was obtained in the same way as for fresh concrete.

Punkte test first was done with the two coarse fractions of quartz $A \& B$, until the optimal composition with less free voids $\mathrm{AB}_{\text {mix }}$ was obtained. $\mathrm{AB}_{\text {mix }}$ was gradually mixed with fraction $C$ until secondary optimum $\mathrm{ABC}_{\text {mix }}$ was achieved. Then $\mathrm{ABC}_{\text {mix }}$ was gradually mixed with a powder fraction $\mathrm{D}$, until final optimum $A B C D_{\text {mix }}$ was reached. First coarse mixing was done by changing the mass concentrations of fractions by $10 \%$. As near-maximum packing, changing the ratio of coarse and fine aggregates has less effect on the resulting packing density, so the step of the concentrations was reduced to $5 \%$, to improve the resolution of the experiment. For every mix of the fillers, at least three tests were done and average values were calculated.

Similar sampling methodology for selection the best quartz filler composition was used during IC testing. Two coarse fractions A \& B of quartz were mixedfirst. Concentrations were iterated with $10 \%$ and the $5 \%$ step until clear $\mathrm{AB}_{\text {mix }}$ was found out. Then the addition of fraction $\mathrm{C}$ to optimal $\mathrm{AB}_{\text {mix }}$ was tested the same way, and then the same was done for the addition of powder fraction $\mathrm{D}$ to optimal $\mathrm{ABC}_{\text {mix }}$. For every mix of the quartz fractions, at least three tests were done and the average packing value was calculated. The experimental density of each mix fraction was measured using sample weighting.

KERN EMS 12K0.1. electronic weights with the precision of $0.1 \mathrm{~g}$ were used for weighing of samples. Control model 54-C0252/C gyratory compactor with the sample cylinder diameter $100 \mathrm{~mm}$ and working pressure of 4 bar was used for intensive compaction testing. All samples were subjected to 160 gyratory cycles. Aalborg CEM I 52.5R white cement with the dosage of $800 \mathrm{~kg} \cdot \mathrm{m}^{-3}$ was used for compositions, as Portland cement CEM I with the strength class of at least 52.5 is advised to be used by literature [7]. Fixed water to cement ratio of 0.25 was chosen, as it provided optimal consistency and workability of concrete slurry. Stachement SP41 plasticizer with a concentration of $3 \%$ was used to improve the workability of the obtained fresh concrete slurry. The compressive strength of the concrete was evaluated after $24 \mathrm{~h}, 48 \mathrm{~h}$ and 7 days following the standard EN 12390-3. 


\section{Results and discussion}

In Punkte test the water demand for saturation can be accepted to be proportional to relative \% of free voids, and was expressed versus the mass fraction of addition of the finest fraction to mix. The results showed a characteristic tendency that at a certain proportion of fractions there is a clear minimum evident, indicating the optimum mix with less free voids (see Fig. 3-5). The optimal proportion of $A_{B}$ mix between fractions $A \& B$ was found in the proximity of proportion $A_{75} / B_{25} \%$ (see Fig. 3). Then fraction $\mathrm{C}$ was added to the $\mathrm{AB}_{\text {mix }}$, until it was found out that $25 \%$ addition fraction $\mathrm{C}$ helps decrease the water demand of $\mathrm{ABC}_{\text {mix }}$ for another $3 \%$ (Fig. 4.). Finally, the powder fraction $\mathrm{D}$ was gradually added to the optimum $\mathrm{ABC}_{\text {mix }}$ and yet another $9 \%$ of reduction of water demand was achieved (Fig. 5) using Punkte test. At least 3 repeated experiments were made for each composition and standard devitations were calculated and shown on the plots.

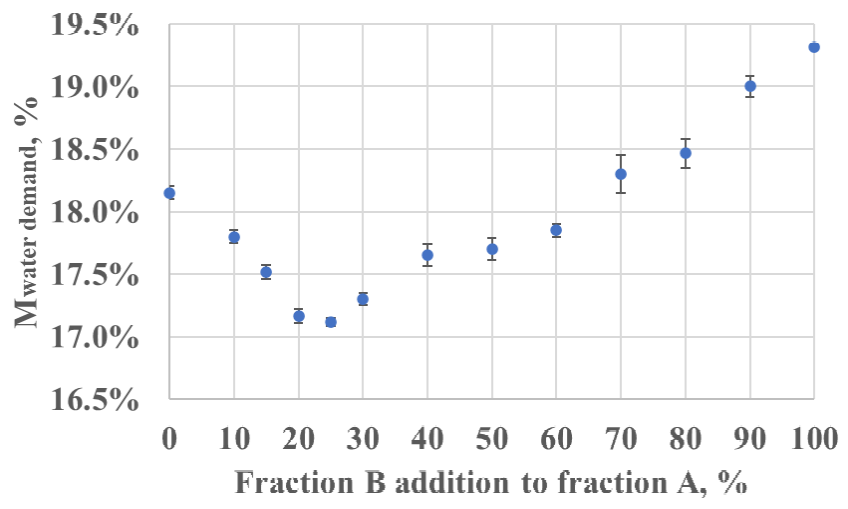

Fig. 3. Water demand for saturation of quartz sand mix consisting of fractions A \& B, obtained by Punkte test

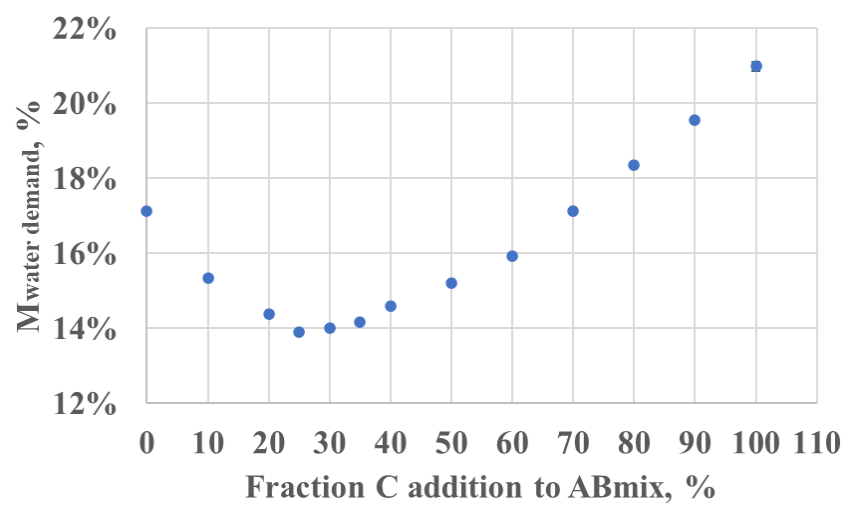

Fig. 4. Water demand for saturation of quartz sand mix consisting of fraction $\mathrm{AB}_{\text {mix }} \&$ fraction C. Obtained by Punkte test

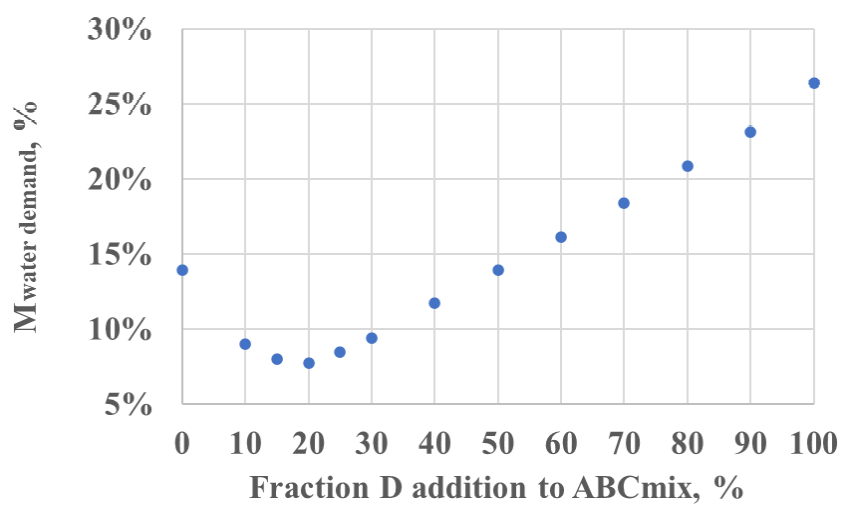

Fig. 5. Water demand for saturation of quartz sand mix consisting of fraction $\mathrm{ABC}_{\text {mix }}$ \& fraction $\mathrm{D}$. Obtained by Punkte test 
In IC test $\%$ of free voids were expressed versus the mass fraction of addition of the finest fraction to mix. The results although showed a characteristic tendency that at a certain proportion of fractions there is a minimum evident, indicating the optimum mix with less free voids (see Fig. 6-8). The optimal proportion $\mathrm{AB}_{\text {mix }}$ between fractions $\mathrm{A} \& \mathrm{~B}$ was in the proximity of proportion $\mathrm{A}_{50} / \mathrm{B}_{50 \%}$ (see Fig. 6). Then fraction $C$ was added to the $A B_{\text {mix }}$, until it was found out that $30 \%$ addition fraction $C$ helps decrease the void content for $\mathrm{ABC}_{\text {mix }}$ for another $5 \%$ (Fig. 7.). Finally, the powder fraction $\mathrm{D}$ was gradually added to the optimum $\mathrm{ABC}_{\text {mix }}$ and yet another $15 \%$ of reduction of void content was achieved (Fig. 8) using IC test. At least 4 repeated experiments were made for each composition and standard devitations were calculated and shown on the plots.

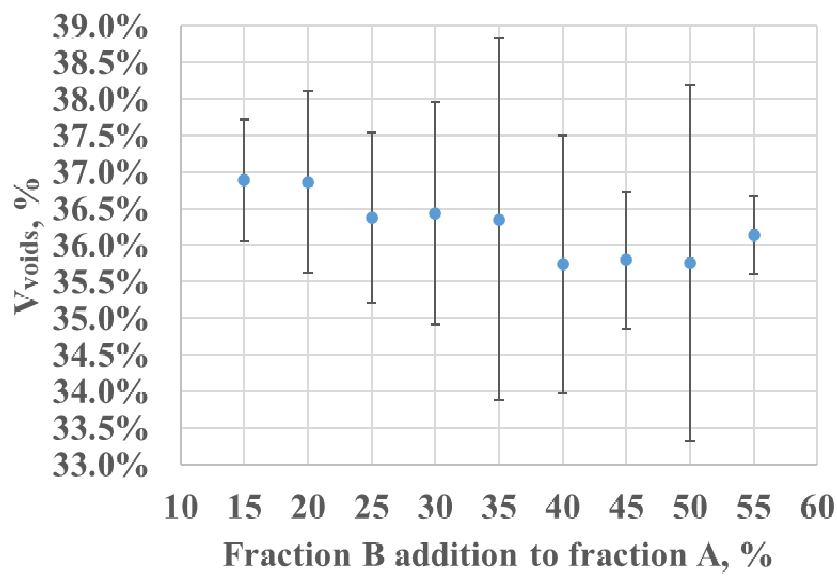

Fig. 6. Volume concentration of voids of quartz sand mix consisting of fractions A \& B. Obtained by IC test

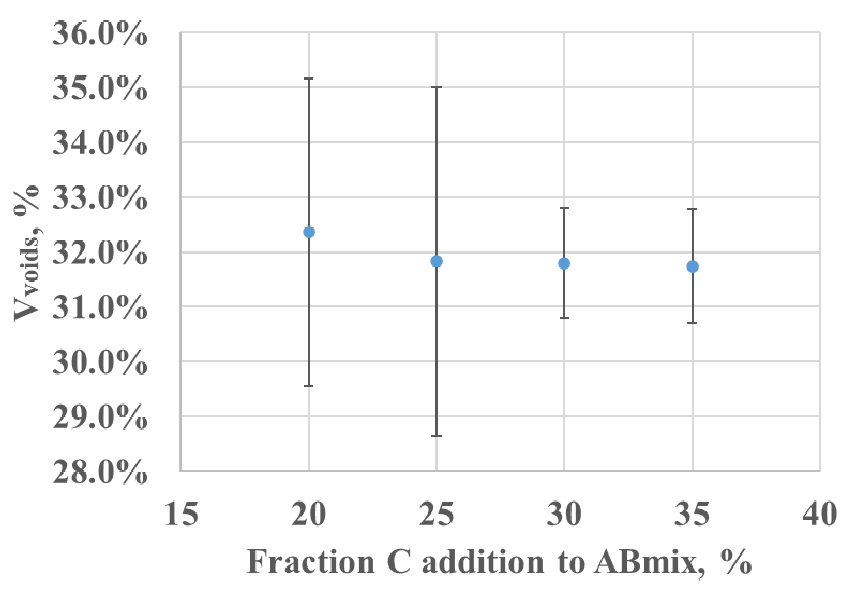

Fig. 7. Volume concentration of voids of quartz sand mix consisting of fraction $\mathrm{AB}_{\text {mix }} \&$ fraction C. Obtained by IC test

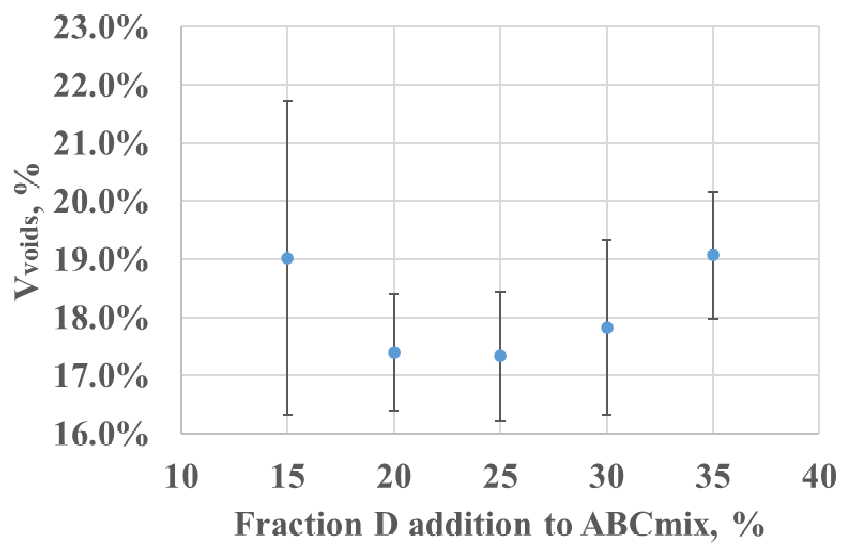

Fig. 8. Volume concentration of voids of quartz sand mix consisting of fraction $\mathrm{ABC}_{\text {mix }} \&$ fraction $\mathrm{D}$. Obtained by IC test 
The optimal grading compositions obtained with Punkte test and IC test were combined and are shown graphically (Fig. 9).

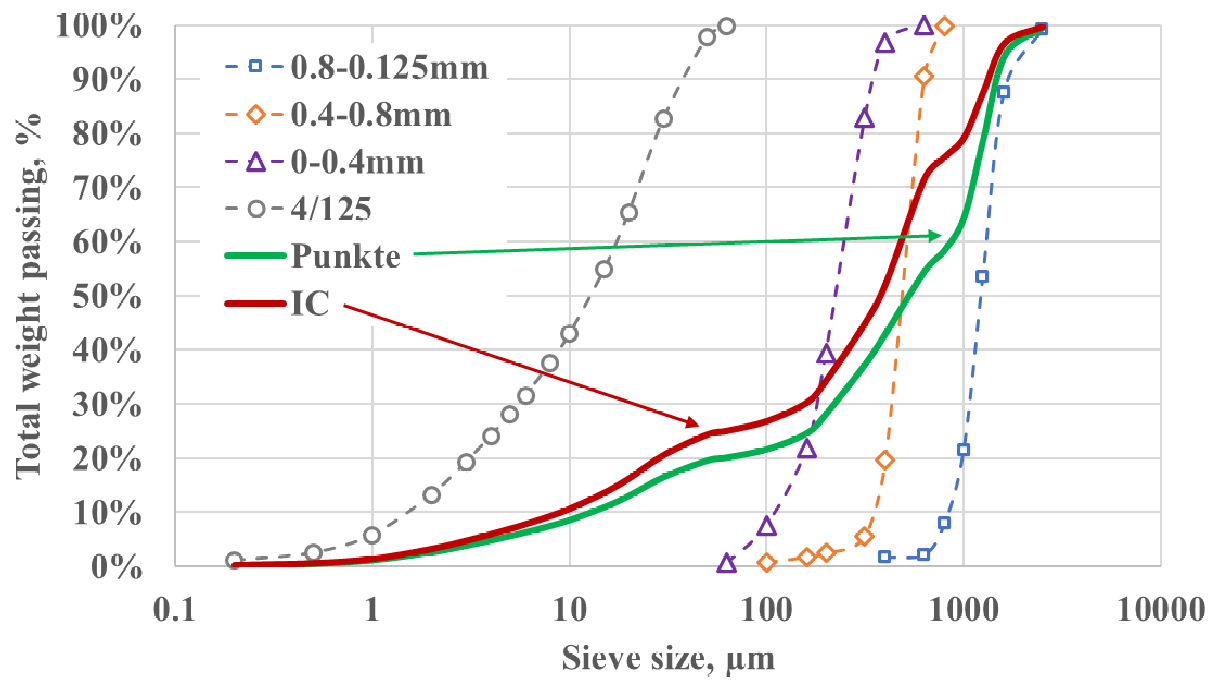

Fig. 9. Combined grading curves of packing optimized mixes of 4 quartz fractions according to experimental results of Punkte test and IC test

It can be seen, that the results of the IC test lead to mix with finer aggregate structure, and the Punkte test - coarser aggregate structure. This may be attributed to the fact that the IC tester uses a dry sample, and larger particles interlock together due to friction, thus larger fractions of smaller particles are necessary to fill the voids to improve packing in the dry mix. On the other hand - during Punkte test added water helps arrange the larger particles into a more compact structure, thus a smaller amount of smaller particles is necessary to improve the packing. There is lack of comparability between these two tests used, because one of them refers to the proportional mass of water, which is proportional to the void content, as the second of them refers directly to the void content in the sample. Despite that, both methods are suitable for aggregate packing optimisation and the UHPC mix design, where aggregates are smaller than a few millimetres.

Based on the data of Punkte test and IC test, the corresponding concrete mixes Mix1 and Mix2 were designed and their compressive strength was evaluated.

Table 3

\section{Composition and compressive strength properties of concrete mix Mix1 and Mix2}

\begin{tabular}{|c|c|c|c|}
\hline Material & Mix1 & Mix2 & \multirow{2}{*}{ Units } \\
\hline CEM I 52.5R cement & 800 & 800 & \\
\hline Fraction A & 635 & 370 & \multirow{2}{*}{$\mathrm{kg} \cdot \mathrm{m}^{-3}$} \\
\hline Fraction B & 201 & 352 & \\
\hline Fraction C & 270 & 303 & \\
\hline Fraction D & 233 & 291 & \\
\hline Stachement SP41 & 24 & 24 & \\
\cline { 1 - 3 } W/C ratio & 0.25 & 0.25 & \multirow{2}{*}{ MPa } \\
\hline \multicolumn{3}{|c|}{ Test results } \\
\hline 24h strength & $73.01 \pm 0,52$ & $76.83 \pm 9.26$ & \\
\hline 48h strength & $90.14 \pm 1.81$ & $86.73 \pm 4.2$ & \\
\hline 7d strength & $102.56 \pm 4.98$ & $100.86 \pm 1.68$ & \\
\hline
\end{tabular}

Slightly higher compressive strength shows Mix1, which has been optimized by Punkte test. This may be attributed to the fact that UHPC belongs to the group of self-compacting concretes, which are cast without intensive compaction - similar to Punkte test sample suspension.

Despite the fact that there were no micro and nanofillers incorporated, the compressive strength of both mixes was comparable to similar results from other authors $[2 ; 8]$. 
Corresponding research using the presented test methods should be continued with micro and nanofillers to investigate the packing density in finer aggregate range.

\section{Conclusions}

1. The optimization of the packing density of coarse aggregates can be done effectively using both methods- either Punkte testor IC test.

2. According to the experiments performed, the Punkte test method required less material to be used in each iteration, thus making it more suitable when only a small portion of fractions are available. The test can be done easily in the field. On the other hand, it requires skilled personel to avoid human error affecting the results. Nevertheless, the results of the Punkte test showed less dispersion and good repeatability over the series of samples.

3. There is a possibility to improve the results of the Punkte test, to make the results directly comparable to the results of the IC test. If the experimental density of the mix is determined, the volume of water necessary for saturation could be expressed versus the total volume of dry mix, indicating the relative void volume using both methods.

4. IC testing of dry filler fractions can be successfully adopted for optimisation of their packing factor. The method includes less human factor, as it can be done using standardised procedure. However, it requires special stationary equipment and larger sample amounts to be available for batching.

5. Further optimization of UHPC involves the introduction of micro and nanofillers and adjustment of the cement paste volume and W/C ratio.

6. The commercially available fractioned quartz aggregates from local origin can be successfully used to develop coarse packing optimised UHPC with high compressive strength.

\section{Acknowledgements}

In accordance with the contract No. 1.2.1.1/18/A/007 between "Competence centre of smart materials and technologies" Ltd. and the Central Finance and Contracting Agency, concluded on $23^{\text {th }}$ of April, 2019, the study is conducted by "Dzelzsbetons MB" Ltd. with support from the European Regional Development Fund (ERDF) within the framework of the project "Competence centre of smart materials and technologies".

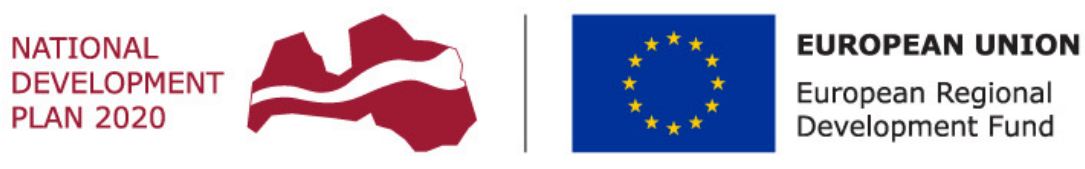

I NVESTING IN YOUR FUTURE

\section{References}

[1] Fehling E., Schmidt M., Walraven J., Leutbecher T., Frohlich S. Ultra-High Performance ConcreteUHPC. Berlin: Wiley, 2014. 188 p.

[2] Nilsson L. Development of UHPC concrete using mostly locally available raw materials. Degree project in Luleå University of Technology, Department of Civil, Environmental and Natural Resources Engineering, Finland, 2018.

[3] Latvian environmental, geological and meteorological agency [online][11.02.2020] Available at: https://www.meteo.lv. l $^{-1}$ apas/geologija/derigo-izraktenu-atradnu-registrs/

[4] Puntke W. Wasseranspruch von feinen Kornhaufwerken (Water requirement of fine granular media). Beton, vol. 52 (5), 2002, pp. 242-248. (In German)

[5] Pakkinen I. Intensive compaction tester - device for testing the compactibility of no-slump concrete, Helsinki, 1986.

[6] NT BUILD 427, Concrete, fresh: Compactibility with IC-tester, Description of Nordtest method, 1994.

[7] Siddique R., KhanM. I. Supplementary Cementing Materials. Berlin, Heidelberg: Springer Berlin Heidelberg, 2011. $287 \mathrm{p}$.

[8] Syed A. Development of Ultra High Performance Fiber Reinforced Concrete. Master thesis. Espoo, Finland, 2018. 88 p. 